\title{
High-Dose Pulse Corticosteroid Therapy: Is It Indicated for Severe Alopecia areata?
}

\author{
A. Friedli D. Salomon J.-H. Saurat \\ Department of Dermatology, Geneva, Switzerland
}

In this issue of the journal, Seiter and his group report their experience with high-dose pulse corticosteroid therapy in the treatment of severe alopecia areata (AA) [1]. They treated 30 patients with intravenous methylprednisolone on 3 consecutive days at 4-week intervals for at least 3 courses; $67 \%$ of their patients with AA plurifocalis showed $>50 \%$ regrowth of hair, but none of the patients with either AA totalis or AA universalis responded to therapy.

Using systemic corticosteroids for AA is not a new concept [2]. To avoid the side-effects of prolonged high-dose oral corticosteroids, intravenous pulse therapy has been proposed [3-5]. The work of Seiter and his group confirms that high-dose pulse corticosteroids are well tolerated without major side-effects and seem to show activity in the multifocal form of AA, but they have no effect on universal AA.

Their paper further indicates that not only recent multifocal forms can benefit from such a treatment, since Seiter et al. observed higher response rates in patients suffering from long-lasting disease.

Should therefore every case of severe AA except the universal form receive high-dose pulse corticosteroid therapy?

As the exact aetiology of AA is not clear [6], we do not know what we treat. Moreover, there are only hypotheses on the mechanism of action of high-dose pulse corticoste- roids in AA, and the available data are not evidence based [5]. It is well known that the clinical course of AA is extremely variable; thus, in a study on the natural history of AA, Muller and Winkelmann [7] found an overwhelming tendency for regrowth of hair with the exception of AA totalis and AA universalis. Therefore risks and benefits of any treatment for this benign, though distressing, disorder have always to be well balanced. For all these reasons, treating severe AA or, even more, giving guidelines is a difficult task. The use of intravenous methylprednisolone in bolus may respond more adequately to the dramatic ongoing hair loss than other options for severe AA, like PUVA or topical immunotherapy. In contrast to these time-consuming approaches, pulse therapy is simple and can be done on an out-patient basis in only 3 days [5]. We appreciate that this option should better be based on a double-blind study. With the already reported data [1, 4, 5] we would now have the basis for doing so, even if the task is very difficult. As the success rate varies widely from trial to trial, comparing the treatment to a placebo may appear to be the only way to demonstrate the effect. However, according to the new Declaration of Helsinki, approved in October 2000 by the general assembly of the World Medical Association, the benefits, risks, burdens and effectiveness of a new method should be tested against those of the best current prophylactic, diagnostic and therapeutic methods [8]. What is the best available

\begin{tabular}{ll}
\hline KARGER & ( 2001 S. Karger AG, Basel \\
1018-8665/01/2023-0191\$17.50/0 \\
$\begin{array}{l}\text { Fax +41613061234 } \\
\begin{array}{l}\text { E-Mail karger@karger.ch } \\
\text { www.karger.com }\end{array}\end{array}$ & $\begin{array}{l}\text { Accessible online at: } \\
\text { www.karger.com/journals/drm }\end{array}$
\end{tabular}

J.-H. Saurat, MD, Prof. and Chairman

Clinique \& Policlinique de Dermatologie

Hôpital cantonal universitaire

CH-1211 Genève 4 (Switzerland)

Tel. +41 2237294 22, Fax +4122 3729460 
option for severe AA? Would this be PUVA or topical immunotherapy? If so, how to conduct the trial? Would any institutional review board allow such a trial in the current new context? Before this trial is conducted, if ever, the question remains: is there an indication for high- dose intravenous pulse corticosteroid therapy for severe AA? In our clinic, we have continued to use this option, but our previous trials as well as the study of Seiter et al. [1] have taught us that it should not be given in cases of AA totalis and AA universalis.

\section{References}

1 Seiter S, Ugurel S, Tilgen W, Reinhold U: High-dose pulse corticosteroid therapy in the treatment of severe alopecia areata. Dermatology 2001;202:230-234.

2 Dillaha CJ, Rothman S: Therapeutic experiments in alopecia areata with orally administered cortisone. JAMA 1952;150:546-550.

3 Burton JL, Shuster S: Large doses of glucocorticoid in the treatment of alopecia areata. Acta Derm Venereol 1975;55:493-496.
4 Perriard-Wolfensberger J, Pasche-Koo F, Marinetti C, Labarthe MP, Salomon D, Saurat JH: Pulse of methylprednisolone in alopecia areata. Dermatology 1993;187:282-285.

5 Friedli A, Labarthe MP, Engelhardt E, Feldmann R, Salomon D, Saurat JH: Pulse methylprednisolone therapy for severe alopecia areata: An open prospective study of 45 patients. J Am Acad Dermatol 1998;39:597-602.
6 Madani S, Shapiro J: Alopecia areata update. J Am Acad Dermatol 2000;42:549-566.

7 Muller SA, Winkelmann RK: Alopecia areata: An evaluation of 736 patients. Arch Dermatol 1963;88:290-297.

8 Enserink M: Helsinki's new clinical rules: Fewer placebos, more disclosure. Science 2000; 290:418-419. 